\title{
Research on Analysis of Higher Vocational Analog Circuit Technology Curriculum Reform
}

\author{
CHEN Xuechang ${ }^{1, a}$ \\ ${ }^{1}$.Institute of Applied Electronics, Chongqing College of Electronic Engineering; Chongqing 401331, China \\ a.Email: pcboy2004@126.com
}

Keywords: Curriculum Reform; Analog Circuits; Teaching Methods

\begin{abstract}
With the rapid development of science and technology, the pace of development of electronic technology is constantly improving the reform direction and intensity of the development of digital circuit technology, electronic technology has important implications Higher Vocational Colleges of digital circuit course, for contemporary high digital circuit training quality personnel vocational schools has a direct relationship to the paper analyzes the reform of Higher Vocational courses digital circuits in the title of the status quo in vocational curriculum reform digital circuit analysis. Features analog circuit technology is the concept of multi-course, teaching more abstract content, limited by hours, the progress of teaching the course is relatively fast, so students generally feel hard to learn the course. To solve these problems, in order to achieve the training objectives of higher vocational education, meet the needs of circuit technology rapid development, analog circuit technology courses teaching content, teaching methodology and teaching methods and practice teaching, etc.
\end{abstract}

\section{Theoretical Introduction of Analog Circuit Technology}

Higher vocational education is an important part of higher education, higher vocational education to higher education and vocational education has dual properties, to develop production, construction, services, high-skilled talents management of the first line is the main task. Information technology as analog circuits, application circuits, communications, electrical engineering and other specialty a very strong theoretical and practical basic course, the students follow professional courses prerequisite occupy much throughout the curriculum system important position.

For the electronic majors in terms of digital circuit is a basic course, but also a strong practice session two electronics-related majors only knowledge of digital circuits to other professional disciplines for effective learning two digital circuit course focused on the basic principle of the circuit and the analysis method of the logic circuit, etc., for electronic professional quality of students will be to improve two of these knowledge students engaged in an important theoretical basis for electronic specialty related work in the future, an important theory is the students' practical guidance given the state of the digital circuit reform in higher vocational schools unscientific problems, selection of digital circuits course reform as research subjects have a certain educational value in higher vocational schools ${ }^{[1]}$.

Analog circuit technology curriculum applies the new project teaching method, which is an electrical circuit effective curriculum teaching reform exploration. Through project teaching, teaching methods reform the traditional theory and practice phase separation, so that students learn by doing, learn to do one, will help improve students' ability to solve practical problems. Analog circuit technology courses project teaching reform of higher education reform in other electrical circuits professional courses there are some inspiration. Implementation of the project will help improve the pedagogy student learning motivation, the ability to solve practical problems, in line with the goal of higher vocational education personnel training.

\section{Main Problem Analysis of Traditional Teaching}

Current teaching analog circuit technology course, although many, but most of all with reference to the preparation of teaching colleges, universities and vocational training objectives and colleges there is a difference, which leads to problems on teaching content: First, too much emphasis on the 
completeness of the knowledge of analog circuits, resulting in primary and secondary teaching content is unclear, and thus make the student can't grasp the main elements in the learning process. Second, too much emphasis on theoretical knowledge, a lot of abstract concepts and theoretical derivation process, increasing the difficulty of vocational students to learn, hard to understand the course and lose interest in learning ${ }^{[2]}$. Fig. 1 shows main problem with traditional teaching.

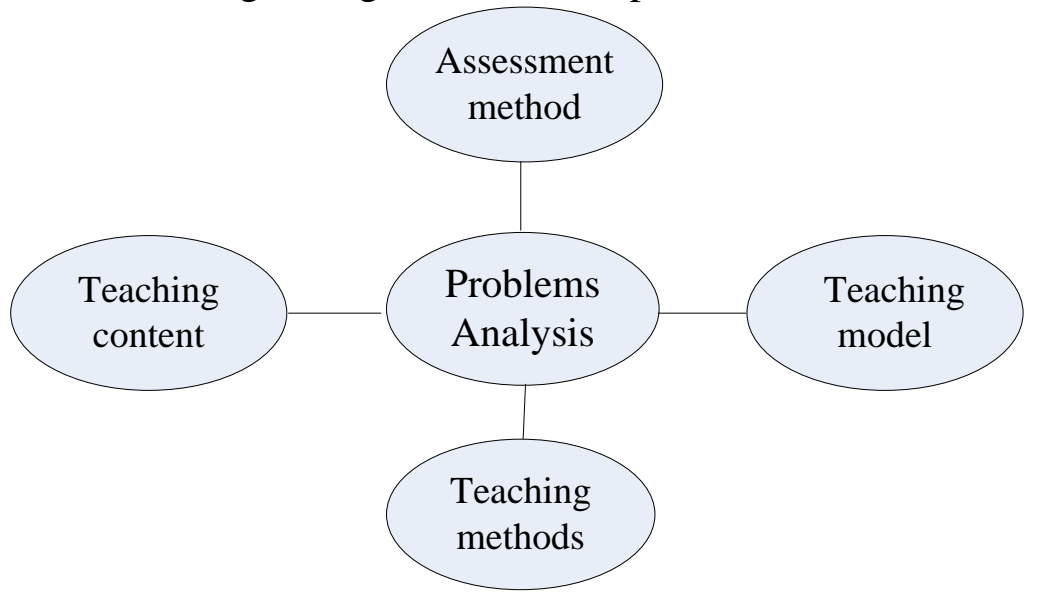

Fig. 1.The main problem with traditional teaching

Analog circuit technology course traditional teaching method is theoretical teaching, and experimental teaching phase separation, it is the theory of teaching in regular classroom teaching, teaching and experiments performed at the experimental training room. Some even Theoretical and Experimental Teachers are not the same, the consequences of theoretical teaching and experimental teaching completely out of touch, students can't understand the theory of learning, in turn leads to the smooth and successful completion of the experiment can't experiment, and thus achieve the purpose of learning.

Traditional teaching methods analog circuit technology curriculum is "chalk + blackboard" model, which teaching methods to facilitate direct exchanges of students and teachers, and real-time change due to the characteristics of the analog circuit technology course, a lot of abstract concepts and internal components motion of particles, it is difficult using traditional blackboard teaching articulated and, therefore, find it hard to teachers in the teaching process, students in the learning process but also find it difficult to understand. Analog circuit technology curriculum final assessment methods maybe the general written, experimental hardly make assessment. However, the teaching curriculum assessment is an indispensable part of it is to check the quality of teaching and teachers assess students' academic level is an important indicator, is the real test whether students into courses of learning tasks, whether the purpose of an important means of teaching curriculum implementation ${ }^{[3]}$.

\section{Curriculum Reform Analysis}

The traditional teaching model emphasizes the candidate leading role of teachers, while ignoring the main role of students, focus on imparting knowledge and despise ability. Students have passive recipients of knowledge, lack of initiative to learn, interest in learning is not high, poor learning outcomes. Further, since the practical analog circuit technology courses is very strong, so the teachers in the teaching concept to achieve four different transitions. Fig.2 shows intelligent community platform. 


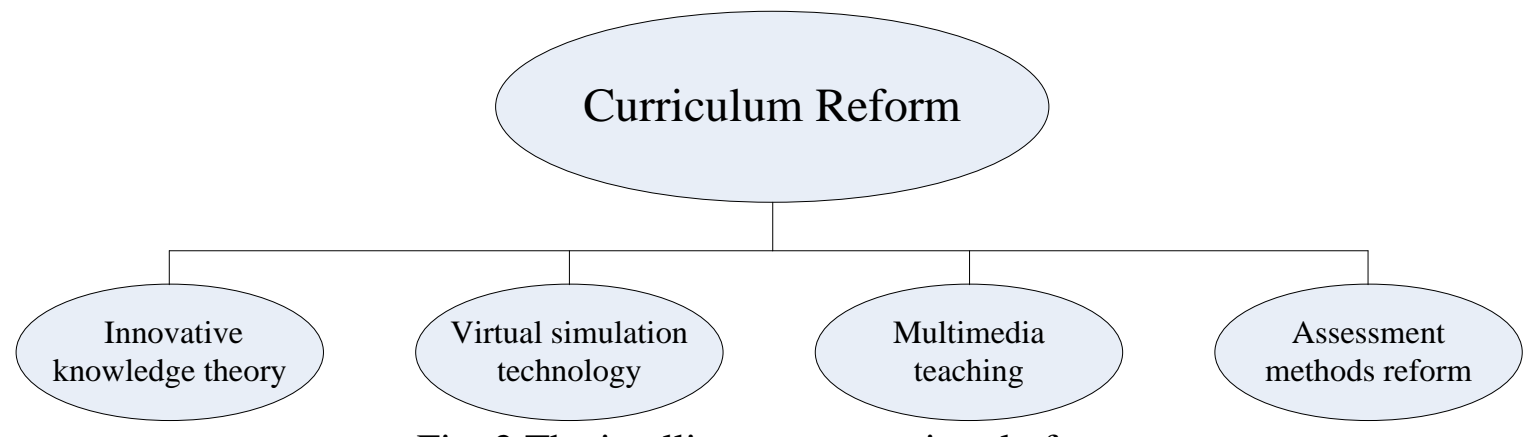

Fig. 2.The intelligent community platform

Based on analog circuit technology in teaching contents of the problems surrounding the vocational education and training for the first line of production of high-quality skilled talents goal, to change the traditional teaching ideas and concepts, teaching contents analog circuit technology curriculum reform, the new theory of knowledge is complemented by front small experiment with the theory related, before explaining a new theory of knowledge, let the students hands-on implementation, and then introduce the necessary theoretical knowledge, while reducing or removing unnecessary theoretical derivation. In each of the last knowledge are currently introducing new technical developments related to the knowledge, to enable students to understand the development trend of new technologies.

Multimedia technology can be used to design and produce analog circuit technology teaching software which courses through flash technology abstract theory of dynamic analog circuit technology, visualization, changing students' information processing model to promote knowledge and understanding memory, perceptual enhancement circuit, in order to stimulate students' interest in learning. Software mainly used by teachers and students after school classroom version using two portions constituting the network version. Through classroom teaching software flash, color pictures and other multimedia curriculum in complex ways and abstract, difficult concepts into specific, observable animation, graphics, abstract visual presentation of knowledge out, thus greatly improving the effectiveness of teaching. We can try to reform the Assessment: final examination results usually score a theoretical written examination 30\% + 30\% + 40\% practical operation. Among them, the usual result is mainly composed of students usually study the situation, to the course and usually constitute experimental conditions; mastery of theory written examination students basic theoretical knowledge, subject to a final written exam; hands-on curriculum assessment of students basic experimental and instrumentation to grasp the situation, according to the students operate in conjunction with the students reply clear conditions given results ${ }^{[4]}$.

\section{Additional Safeguard Measures}

Using the Internet course builds students' self-learning platform. Analog circuit technology curriculum more theoretical knowledge, after the implementation of the integration of theory and practice of teaching, tend to weaken the basic knowledge, the use of online courses build students' self-learning platform can guide students to independent learning, forming a necessary complement to the curricular learning. Analog circuit technology network course includes discussion, Q \& A, resources, chat, etc., which contains the syllabus curriculum resources, teaching characteristics, circuits lesson plans, multimedia teaching lesson plans, test database, exercises, practice project, a comprehensive training program and after school job counseling.

Open practice after school classroom operations, increase students' hands-on opportunities. Since the analog circuit technology course hours less task tight, slow part of the learning progress of student curricular unable to complete the task. Open practice after school classroom operations, allows students to have enough time to finish the project, the full commissioning, final training given satisfactory report. Open twice a week, each time for an afternoon or two classes, two mountain better performance, ability to manage and guide the students. This will not only help students make between each other, promote each other, but also reduce the burden on teachers ${ }^{[5]}$. 
Based on insufficient, analog circuit technology reform traditional teaching methods can be present embodiment: first, carry out the integration of teaching, to achieve theoretical teaching and practical teaching combined. Teachers change the traditional mode of theoretical courses and practical courses on separate, integrated curriculum in the classroom teaching on synchronous operation. Virtual simulation system is mainly to solve two aspects of this issue: allow students to use the docking ask extracurricular experiment soon to be familiar with, mainly through building a network simulation platform virtual; secondly, during the experiment allow students hands-on experience before actually using laboratory simulation software to provide simulation experiment.

\section{Conclusions}

Higher Vocational analog circuit as a theory and practice closely integrated professional foundation courses, the traditional teaching mode of teaching, the effect is not ideal. For the characteristics of the course, teaching content integration, reform the traditional teaching methods, so that theory and practice teaching together organically, thus ensuring the teaching and achieved good results. Emphasis on traditional teaching methods in academic disciplines, from the theory and practice, it is difficult to adapt to the characteristics of vocational college students. Teaching Reform after the occupation of the construction task based learning content, requires teachers in teaching activities according to professional positions knowledge and skills requirements, from typical occupational tasks in the rational design of teaching project; students under the guidance of teachers in accordance with the actual complete program working process, complete the teaching program will help achieve the goal of teaching students appropriate positions of professional competence and quality requirements.

\section{References}

[1] Wei Ya fang. Higher Vocational analog technology reform in teaching [J], Zhejiang Vocational and Technical College, 2008 (3): 55-57.

[2] Hou Ning, Zhang Tianyu, Yang Yong. "Analog technology" Exploration and Practice of Teaching Reformation [J]. Nanning Vocational and Technical College, 2009 (4) 40- 42.

[3] W. G. Beazley, vocational mechanism professional "Metalworking Training" Teaching Reform Course Day items [J]. Wenzhou Vocational and Technical College, 2010 (3), 86-88.

[4] Su Zhihong Project Approach Teaching in electricity technical courses [J], Chinese Science and Technology Information, 2011 (2): 189-190.

[5] H. Y. Huang, Project Teaching Method in "analog circuit technology" Teaching [J], Chinese Science and Technology Information, 2013 (12): 210-212. 